\title{
PROFESSIONAL TRAINING IN THE NATIONAL EDUCATIONAL SYSTEM IN THE CONTEXT OF ROMANIA'S ACCESSION TO THE EUROPEAN UNION
}

\author{
Anamaria BURADA, \\ PhD. Student, Doctoral School of Humanitas Sciences- \\ "Ovidius" University of Constanta, \\ Romania \\ E-mail: anamaria_burada@yahoo.com
}

\begin{abstract}
This article aims to present the way in which Romania harmonizes the European legislative framework presented in previous chapters in the field of professional education and training, the proposed educational strategies, to present the concepts of adult education and professional training of teachers and the procedure for accrediting a lifelong training program. The usefulness of this material lies in the fact that it gathers together this information in a unitary and scientific framework, as it is not only a resource but also a benchmark for further research. Global educational policies are based on lifelong learning, on adult education, on the reconstruction of the vision of relevant, motivating, active and creative learning, on the impact on life and society, as learning is based on authentic experiences focused on results. Education and professional training contribute to the improvement of the capacity to understand values such as solidarity, equal opportunities and social participation.
\end{abstract}

Keywords: adult education; European Union; training;

\section{INTRODUCTION}

In the last years, on the territory of Romania there have been a series of transformation processes both at the level of the society and at the economic level, noticed through the transition to post industrialism and a knowledge-based society, these components representing challenges for the professional education and training. All these represent the expression of the desire for evolution, natural for any emerging society, but equally the expression of the permanent efforts made for alignment with the European framework. Following these efforts, a dynamic educational system will respond to the demands of the society, which is becoming increasingly dynamic.

The reunion of these specific aspects follows the natural direction of the society but also of the increasing volume of information that can be accessed. The elements of risk character can come from the informational fluidity and sometimes its ambiguous character plus the excessive specialization that could lose sight of the elements which make up the general view, attracting potential future conflicts both at the level of ideas and of action processes. 


\section{HARMONIZATION OF LEGISLATION- COMMITMENTS TAKEN BY ROMANIA}

The European dimension was built and developed in the Romanian education over time, it is not new, but it has acquired new connotations in the context of European integration (Tudorică, 2004, p.11).

30 years after the end of the communist era in Eastern Europe, 12 years after joining the European Union, Romania is in a permanent reform regarding the Romanian education. The reforms often contradict the previous reforms and do not continue them. Changes in the level of an educational system contribute to the changes of the society and these can be visible in the long term. Over time, there have been numerous changes in the laws of education, the tendencies to harmonize the national practices with the international ones, the need to highlight the international dimension, the globalization, the compatibility of the Romanian education system with the European one.

The legislative basis by which the Romanian state grants the right to education is represented by S.32 of the Constitution of Romania. The year 2011 brought about Law no. 1 of the National Education, law that united the old law of education with the status of the teacher, based on which the entire education system in our country is organized.

In the current context, taking into account the major role that professional training plays for Romania's economic and social development, the experiences accumulated in the previous period, the rethinking of vocational training should be correlated with the Strategy for education and professional training in Romania proposed for the period 2016-2020, because it addresses in an integrated way the field of initial and lifelong professional training. Permanent assessments have the role of regulating the professional training and specialization of individuals.

Professional training is developed in organized manner and is offered by different agents, in compliance with the standard rules. The financing of these professional training programs is supported either from structural funds or from the state budget, either by the employer but also by the direct beneficiaries, depending on their type, duration, purpose and utility. Because education was one of the major chapters with which, in March 2000, negotiations for Romania's accession to the European Union began, compatibility with European organizations and performances represented an important point of debate. Some examples are OMEN 3621/13.04.2000, which led to the systematic introduction of elements of European studies in the curriculum of schools, colleges and universities in Romania, OMEN 3685/26.04.2000, which provided for the setting up of Lifelong Training Centres in European Studies.

Romania signed the Bologna Declaration (1998) and the Florence Declaration (1998) on the creation of the European educational space and in Bucharest, and between June 18-20, 2000 the Conference of European Ministers of Education was held, which was entitled "Quality of education social cohesion". This has led to the underlining of the importance of education in European countries and of the extent to which educational policies can be promoted and supported by each government, in the context of the need to improve the quality and increase access to training (Tudorică, 2004, p.53).

In 2009, the Commission prepared the Strategic Framework for European Cooperation in the field of professional education and training, which highlights the role of professional education and training policies in increasing productivity and sustainable development (ET20202). 
Addressing the European dimension of education through the mobility of people, the recognition of qualifications and diplomas, harmonization of structures, consideration must be given to how our education system harmonizes with European standards by analysing documents and reports such as the Monitorul educației și formării din 2018 (Education and Training Monitor of 2018) and strategies such as the Strategy of Professional Education and Training for the period 2016-2020 and the Europe 2020 Strategy. This alignment involves building performance in terms of content, methods, discipline plans and professional training programs.

\section{2025-PERSPECTIVES - THE ROLE OF EDUCATION IN THE CHANGE PROCESS. CONTINUOUS TRAINING OF TEACHING STAFF}

The social-political, economic and cultural reform in the system of the Romanian society has determined global and profound transformations at the level of the education system, the human factor proving to be the valuable resource of the changes (Constandache, 2006, p. 7). Teacher training represents an indispensable strategy for developing the quality of education. Quality in education also implies its power of differentiation according to the level of training, of the competences required on the labour market since the educational systems are characterized by dynamism. The Romanian education system is included in the comparative studies carried out by the European Commission, these reflecting the common tendencies in the process of initial and lifelong training of teachers, but also elements of national orientation.

Both the Romanian education system and most of the European education systems will be on the short term in the situation of facing new challenges. Massive population migration and the influx of migrants result in multicultural challenges. Different values, different backgrounds, different beliefs and language spaces can raise barriers, but they must in fact become opportunities for educational development rather than barriers. We consider that this step can only be achieved if we previously prepare specialists and teachers from an intercultural perspective. Thus, a more tolerant universe for differences can be born, but also a much easier integration of the new population groups, which will lead to a natural evolutionary process, cancelling potential conflicts. Of course, those responsible for organizing these educational policies are the representatives of the governing bodies, both politicians and opinion leaders.

Lifelong professional development is regulated by S.242 of the Law of National Education no 1/2011, as subsequently amended and supplemented, the lifelong formation representing both a right and an obligation according to the legislation in force, Order 5562/2011 assuming the obligation to accumulate 90 credits in the last 5 years of activity. Labour Code - Law 53/2003, republished, provides that employers must provide employees access to professional training.

The main institution involved in lifelong learning is the House of the Teaching Staff, which operates on the basis of the Minister's Order number 5554 of 2011, a provider of lifelong training programs at national level.

A condition of the training programs is to allow the mobility of the learner both vertically and horizontally. Horizontal mobility allows attending courses that are not available in the institution of origin. Vertical mobility refers to the possibility of reducing the standard duration of university residence, as long as the minimum transferable credits are accumulated. This would encourage the development of research institutions, the 
development of alternative systems, such as distance learning (Iucu, 2004, p.23). This is of real utility as it responds to the obvious needs of the beneficiaries, uses the intelligent technology, offers flexibility from a temporal point of view and allows good communication between beneficiaries and trainers.

The Order of the Minister no. 5561 of 2011 regulates the Methodology regarding the lifelong training of the personnel from the pre-university education which states that they have the right to participate in any of the forms of training/organization of lifelong training/improvement in the country but also abroad, by participating in the mobility within the European programs. Access to these facilities is open to all interested parties and there are no barriers or restrictive conditions.

"Changes can be inevitable in any field, but what we want from life and from the European values we value remains unchanged. We want a society where peace, freedom, tolerance and solidarity are above all else. We want to live in a democracy where there is a diversity of views and a critical, independent and free press. We want to be free to express our opinion and to be sure that no person or institution is above the law. We want a Union in which all citizens and all Member States are treated equally. We want to ensure our children a better life than the one we have lived." These statements bring along with them a high degree of responsibility for the factors that guarantee them.

On November 26, 2018, the Council of the European Union adopted its position on the Erasmus+ program for the period 2021-2027. The proposed regulation will expand the range of learning opportunities in Europe and beyond, to reach more people compared to the current period. Also, following the extension of the offer, all levels of education and training will be included. In order to underline its inclusive favourable approach, the Council maintained the current name of the program, "Erasmus +". At the December 2017 European Council meeting, EU leaders called for increased mobility and exchanges, including through a substantially enhanced, expanded and inclusive Erasmus + program.

\section{ACCREDITATION OF LIFELONG TRAINING PROGRAMS}

Teacher training is a priority of the Romanian education system, little valued, but in a close correlation with the other components of the education reform. Of course, this process has a speed of achievement influenced by the size of the education system, by the differences of specialization, by the specificity of the human resource and even by the existing relative financial resources.

Credit is a unit of value that tends to indicate the quantity (without making a precise reference to quality) of work, of effort involved by a discipline in relation to the total number of academic requirements necessary to obtain a diploma/certificate/certification, through which the contribution of a subject/topic within the curriculum can be quantified (Iucu, Păcurari, 2004, p.42). The quantity is related to the actual number of hours allocated to the training activities within these specialization programs, regardless of the effective form of training.

The underlying legislation is represented by the Methodology of accreditation and evaluation of training providers, approved by OMECTS no 5564/2011 and the procedure of accreditation of a lifelong training program by the Directorate of Lifelong Learning within the Ministry of National Education, called before CNFP, respectively DFC (Lifelong Education Directorate) and the way in which the participation in the European learning programs is converted into transferable professional credits. 
In addition to central public authorities, lifelong learning also involves other public institutions at regional and local level, as well as social partners and civil society organizations. In order to increase the participation and relevance of lifelong learning, longterm actions are needed, involving all parties, coordinated and sustained effort from all key actors - Ministry of National Education, National Qualifications Authority, universities, lifelong education centres, NGOs. Developing strategies is also a condition for accessing European funds for future programs.

Among the priorities of action of Romania we can mention the promotion of awareness campaigns, the development of an attitude that favours learning and its benefits, the granting of subsidies for training providers and organizations that develop innovative training projects in partnership. Taking also into account the recent results of national and international assessments, we observe an increasing interest in the priority of education, the reduction of the phenomena of school dropout and illiteracy.

The National Lifelong Learning Strategy 2015-2020 has established four directions of action, one being represented by supporting participation in European mobility programs. The professional education and training sector is essential for the achievement of the Europe 2020 objectives, its improvement having an influence on economic growth through employment. Thus, education is preserved as a strategic area for our country.

Even in terms of the training of teachers it must be taken into account that the triangle of knowledge has become innovation, education and technology, the development and the exercise of creativity, of the ability to innovate, of the technological skills, of the capacity to accept the new and to promote it, the adaptability to change. We consider, moreover, that the shortest reaction time can create efficiency in education, which is the appropriate response to the educational challenges that the society gives in relation to the educational system. Education needs to be elaborated at a deep level for all involved and an active monitoring of the smooth running of the process intervenes and regulates the educational system while running. Active partnerships between school, community, parents, turn into real learning scenarios and experiences that contribute to a harmonious development of students. However, counsellors and career counselling and guiding centres appear and manifest in an active manner, namely not only specialists, but also bodies designed to actively support and contribute to training, specialization of beneficiaries through the simulation and construction of career plans but also of alternative paths in professionalization.

At European level there are some new trends and educational policies at the level of the elaboration of the professional training programs of the teaching staff such as the decentralized planning of the training, of the professionalization of the teaching staff by means of the introduction of the research elements, the shift of the focus from acquisition to knowledge of training and development of competences.

\section{CONCLUSION}

The European Union is a unique identity, without historical precedent, dynamic and flexible, the most evolved example of a hybrid entity, which through its dimensions of enlargement, through its elements unites Europe in a multisectoral political, economic, military, cultural, spiritual and social ensemble.

The conclusions we can draw from this article are related to the transformation processes of the society at school and education level, to their internationalization, 
demonstrating the importance of this field in the evolution of the world, showing an overview but also highlighting globally the different cultures of learning and training with an emphasis on Romanian culture. An image on the dynamics of education can only capture a moment of it as the dynamics prove to be permanent and perhaps from this perspective, we can also understand how the reforms in education come and manifest themselves. Of course, the concerns about education will be permanent and are becoming more and more accentuated. Specialization and professionalism obviously bring about high performance.

\section{BIBLIOGRAPHY:}

[1] Constandache, M. (2006) Profesionalism și competență in cariera didactică (Professionalism and competence in the teaching career) Constanța, Ex Ponto Publishing House, 2006, p.7

[2] Iucu, R (2004). Formarea cadrelor didactice. Sisteme, politici, strategii (Teacher Training. Systems, policies, strategies) Bucharest, Humanitas Educațional Publishing House, p. 23

[3] Iucu, R. \& Păcurari, O (2004). Formare inițială și continuă (Initial and lifelong training), Humanitas Educațional Publishing House, 2004, p. 42

[4] Tudorică, R (2004). Dimensiunea europeană a învățământului românesc (The European dimension of Romanian education), Iași, Institutul European Publishing House, , p. 11

[5] Methodology of accreditation and evaluation of training providers, approved by OMECTS no 5564/2011 amended and supplemented by OMECTS nr 3130/2013 and OMECS no. 5442/8.10.2015

[6] European Commission-White Paper on the future of Europe - Reflections and scenarios for the European Union - 27 until 2025, Brussels, 1.3.2017[COM(2017)2025 final] https://www.consilium.europa.eu/ro/press/press-releases/2018/11/26/expanding-and-strengtheningerasmus-council-agrees-its-position/pdf, accessed on December 6, 2019

[7] National Lifelong Learning 2015-2020, https://www.edu.ro/sites/default/files/fisiere\%20articole/Strategie\%20LLL.pdf, accessed on July 2, 2019 